\title{
Modelagem com geometria, google earth e os caminhos mínimos de uma praça pública
}

\author{
Modeling with geometry, google earth and the paths of \\ a minimum public square
}

\author{
Dirceu dos Santos Brito*1 e Lourdes Maria Werle de Almeida ${ }^{2}$ \\ ${ }^{1}$ Mestre, Secretaria de Educação do Estado do Paraná - SEED/PR, Londrina, Brasil \\ ${ }^{2}$ Doutora, Matemática, Universidade Estadual de Londrina - UEL, Londrina, Brasil
}

\begin{abstract}
Resumo
Este trabalho relata uma atividade de modelagem matemática realizada com adolescentes internados em um Centro de Socioeducação no sul do país. Essa atividade exigia dos alunos elaborar um projeto de reforma de uma praça pública com base no problema de encontrar uma rede de caminhos de comprimento mínimo interligando diferentes pontos de acesso da praça aos seus elementos centrais. Investigando imagens aéreas impressas de praças, obtidas no Google Earth, os alunos foram conduzidos ao estudo do problema de Fermat-Steiner. A condução desse estudo, as soluções apresentadas e o desenvolvimento de competências de investigação e compreensão em geometria são discutidos neste trabalho.
\end{abstract}

Palavras-chave: Modelagem Matemática. Otimização Geométrica. Problema de Fermat-Steiner. Google Earth

\begin{abstract}
This paper reports a mathematical modeling activity among teenagers admitted to a Socio-educational Center in the south of Brazil. This activity required the students draft a reform of a public square based on the problem of finding a network of paths of minimum length connecting access points to the plaza to its core elements. Investigating printed aerial images of squares, obtained from Google Earth, students were conducted to study the problem of Fermat-Steiner. The conduct of this study, the presented solutions and the development of research skills and understanding in geometry are discussed in this paper
\end{abstract}

Keywords: Mathematical Modeling. Geometric Optimization. Fermat-Steiner Problem. Google Earth 


\section{Introdução}

A importância de fazer modelagem e aplicações de matemática em sala de aula é apontada por um número significativo de pesquisadores que analisam seu impacto no ensino e na aprendizagem da matemática em seus diferentes aspectos. (BASSANEZI, 2002; ALMEIDA e BRITO, 2005; BARBOSA, 2001). Esses pesquisadores defendem que a inclusão de problemas oriundos da realidade nas práticas escolares de matemática pode capturar $\mathrm{o}$ interesse dos alunos, desenvolver competências e habilidades específicas para resolver problemas, possibilitar a apreciação do poder da matemática e favorecer a compreensão de conceitos e métodos dessa disciplina.

Adicionalmente, os Parâmetros Curriculares Nacionais - PCN do Ensino Fundamental (BRASIL, 1998), PCNEM do Ensino Médio (BRASIL, 2000), PCN+ (BRASIL, 2002) e Orientações Curriculares para o Ensino Médio (BRASIL, 2006) - de Matemática sinalizam que o trabalho com modelagem matemática pode desenvolver competências de "investigação e compreensão" que englobam, segundo esses documentos oficiais,

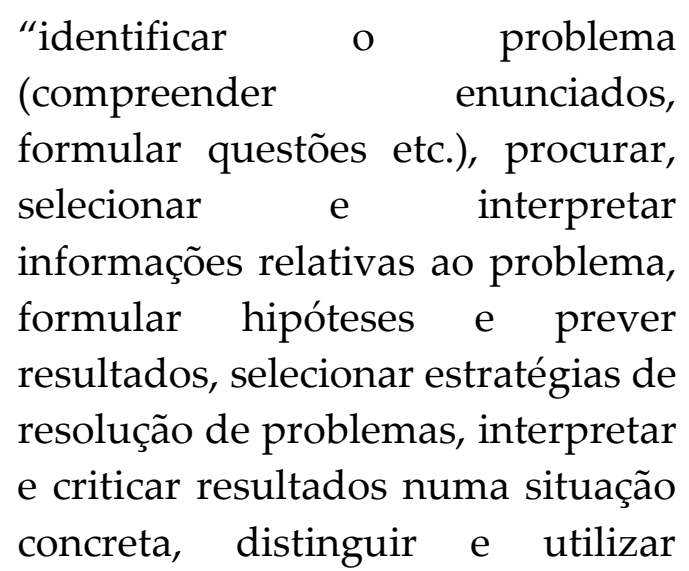

raciocínios dedutivos e indutivos, fazer e validar conjecturas, experimentando, recorrendo a modelos, esboços, fatos conhecidos, relações e propriedades, discutir ideias e produzir argumentos convincentes". (BRASIL, 2002, p. 115-117).

O estudo de problemas reais de otimização, por exemplo, pode despertar a curiosidade e ajudar a desenvolver as competências de investigação e compreensão nos alunos. Esses problemas caracterizam-se pela ação de determinar a melhor opção entre várias alternativas possíveis e, em boa parte dos casos, suas resoluções consistem em obter valores de máximo ou de mínimo que uma função pode assumir num intervalo.

Problemas de otimização costumam ser abordados, no ensino superior, na disciplina de cálculo diferencial e integral. Já no ensino fundamental e médio, esses problemas aparecem nos livros didáticos quase sempre ligados ao estudo das funções quadráticas. No entanto, é possível abordá-los com alunos da educação básica empregando, por exemplo, a desigualdade entre as médias aritmética e geométrica ou recorrendo às soluções geométricas (NIVEN, I. 1981; FIGUEIREDO, D.G 1989).

Este artigo apresenta uma abordagem, via modelagem matemática, do problema de otimização geométrica de Fermat-Steiner com adolescentes internados em um Centro de Socioeducação no sul do país. O objetivo deste trabalho é verificar o desenvolvimento das competências de 
investigação e compreensão em geometria, uma vez que o projeto de modelagem exigia a investigação de imagens aéreas de praças públicas e o estudo do problema de obter caminhos de comprimento mínimo interligando os pontos de acesso aos pontos centrais dessas praças. $\mathrm{O}$ relato completo do desenvolvimento dessa experiência de ensino encontra-se em BRITO (2013).

\section{0 problema de Fermat-Steiner}

De acordo com Courant e Robbins (2000, p. 430) o problema de Fermat-Steiner foi proposto pela primeira vez pelo matemático francês Pierre Fermat (16011665) com o seguinte enunciado:

"Dados três pontos não colineares A, B e C localizados num plano, determine um ponto $\mathrm{P}$ desse mesmo plano de modo que a soma $\overline{\mathrm{PA}}+\overline{\mathrm{PB}}+\overline{\mathrm{PC}}$ seja a menor possível."

A generalização desse problema para $n$ pontos $(n>2)$, não necessariamente localizados num mesmo plano foi apresentada pelo matemático suíço Jakob Steiner (1796-1863). Antes disso, o matemático italiano Evangelista Torricelli (1608-1647) apresentou uma solução geométrica para encontrar um ponto que soluciona o problema de Fermat em duas dimensões. O matemático inglês Thomas Simpson (1710-1761) também provou algumas características importantes do ponto de Torricelli. (COURANT, ROBBINS, p. 430-440).

A solução apresentada por Torricelli é a seguinte: se no triângulo $A B C$ todos os ângulos são menores do que $120^{\circ}$, então
$P$ é o ponto a partir do qual cada um dos três lados $A B, B C$ e $C A$, tomados dois a dois, subentendem um ângulo de $120^{\circ}$. Caso um ângulo de $A B C$, por exemplo, o ângulo em $C$, for igual ou maior do que $120^{\circ}$, então o ponto $P$ coincidirá com o vértice $C$. A Figura 1 ilustra esta solução.

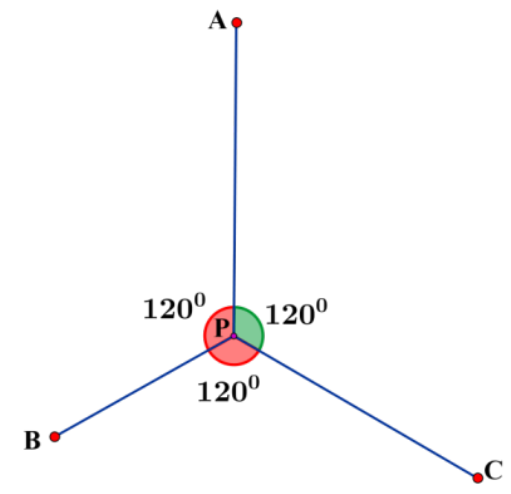

Figura 1 - Conexão do ponto mínimo

$\boldsymbol{P}$ de Fermat-Steiner

Torricelli chegou nessa solução como consequência do conhecido problema de Heron. O matemático grego Heron de Alexandria, que viveu entre 150 a.C. e 250 d.C., mostrou, empregando um argumento geométrico simples, que se a luz deve ir de uma fonte $S$ a um espelho $M M^{\prime}$ e, então, ao olho $E$ de um observador, ela deve seguir o caminho mais curto possível $S P E$ que é aquele em que os ângulos $S \hat{P} M$ e $E \hat{P} M^{\prime}$ são iguais (figura 2).

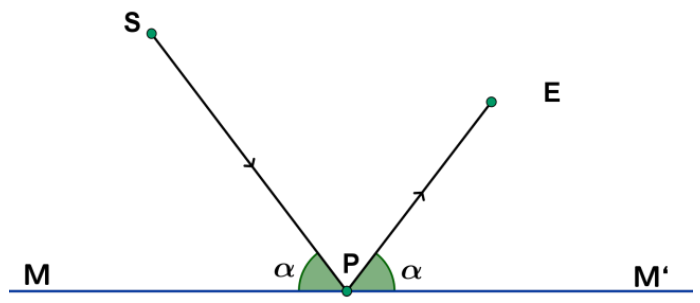

Figura 2 - Caminho mais curto para luz ir de $\mathbf{S}$ a E (Problema de Heron)

Vamos a seguir apresentar duas soluções para o problema de Fermat como consequência do problema de Heron. 
Primeira solução: De fato, sejam $A, B$ e $C$ pontos contidos num mesmo plano. Suponhamos que $P$ seja o ponto mínimo procurado. Construímos um círculo com centro em $C$ e raio igual à distância $\overline{P C}$.

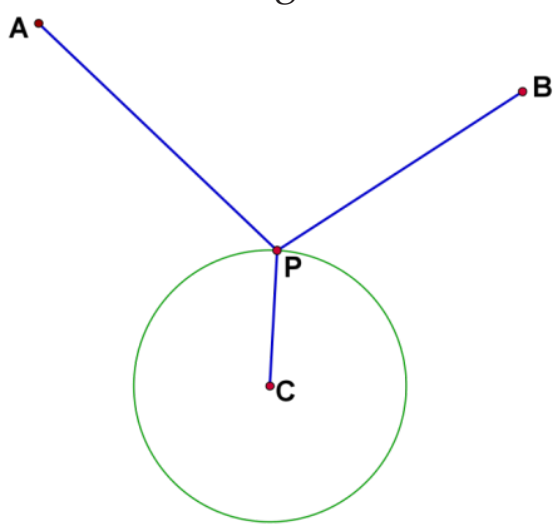

Figura 3: Poligonal $\boldsymbol{A P B}$ tangente ao círculo em $\boldsymbol{P}$.

Observe que $P$ deve ser o ponto tal que $\overline{P A}+\overline{P B}$ seja mínimo. Se $A$ e $B$ estão fora do círculo, como mostra a figura 3 , então, segue do problema de Heron que $P A$ e $P B$ devem formar ângulos iguais com o círculo centrado em $C$. De modo inteiramente análogo, concluímos que, supondo que a soma $\overline{P C}+\overline{P B}$ seja mínima, então $P C$ e $P B$ devem formar ângulos iguais com o círculo centrado em $A$ e raio $A P$, desde que $B$ e $C$ estejam ambos fora desse círculo.

Portanto, supondo que a soma $\overline{P A}+$ $\overline{P B}+\overline{P C}$ seja mínima, resulta em que os ângulos formados pelos segmentos $P A, P B$ e $P C$, tomados dois a dois, são iguais entre si, e consequentemente iguais a $120^{\circ}$.

$\mathrm{O}$ raciocínio utilizado nessa demonstração baseou-se na hipótese de que $A$ e $B$ estão ambos fora do círculo centrado em $C$ e que $B e C$ estão ambos fora do círculo centrado em $A$. É fácil demonstrar que isso sempre ocorrerá desde que todos os ângulos do triângulo
$A B C$ sejam todos menores do que $120^{\circ}$. No caso particular em que algum dos ângulos de $A B C$ seja maior do que ou igual a $120^{\circ}$, então $P$ deve coincidir com o vértice de maior ângulo, pois a soma dos dois lados que formam o maior ângulo de $A B C$ é menor do que qualquer outra soma de dois lados desse triângulo.

Segunda solução: vamos provar que, se os ângulos formados entre segmentos $A P, B P$ e $C P$, tomados dois a dois, medem $120^{\circ}$, então a soma $\overline{P A}+\overline{P B}+$ $\overline{P C}$ é mínima.

De fato, seja $P$ um ponto qualquer localizado no interior do triângulo $A B C$. Girando esse triângulo em torno do vértice $C$, no sentido anti-horário, em $60^{\circ}$, obtemos o triângulo $A^{\prime} B^{\prime} C^{\prime}$, em cujo interior localiza-se o ponto $P^{\prime}$, imagem de $P$, como mostra a figura 4 .

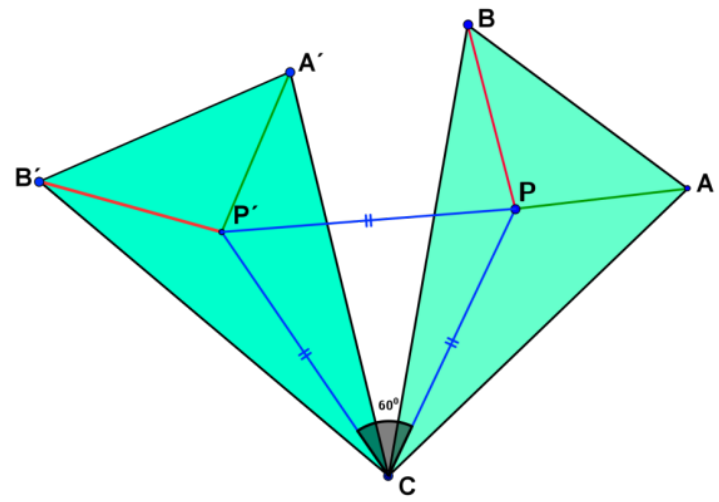

Figura 4 - Rotação do triângulo $\boldsymbol{A B C}$, obtendo-se o triângulo $\boldsymbol{A}^{\prime} \boldsymbol{B}^{\prime} \boldsymbol{C}^{\prime}$

Nessas condições, afirmamos que o triângulo $C P P^{\prime}$ é equilátero. De fato, como $\overline{C P}=\overline{C P^{\prime}}$, segue que o triângulo $C P P^{\prime}$ é isósceles e, desse fato, resulta que seus ângulos da base $P P^{\prime}$ ', têm mesma medida, ou seja, $\operatorname{med}\left(C \hat{P} P^{\prime}\right)=$ $\operatorname{med}\left(C \widehat{P}^{\prime} P\right)$. Mas, como $\operatorname{med}\left(P \hat{C} P^{\prime}\right)=$ $60^{0} \quad$ e $\operatorname{med}\left(C \hat{P} P^{\prime}\right)+\operatorname{med}\left(C \widehat{P}^{\prime} P\right)+$ $\operatorname{med}\left(P \hat{C} P^{\prime}\right)=180^{\circ}, \quad$ conclui-se que 
$\operatorname{med}\left(C \hat{P} P^{\prime}\right)=\operatorname{med}\left(C \widehat{P}^{\prime} P\right)=60^{0}$.

Portanto, o triângulo $C P P^{\prime}$ é equiângulo e, consequentemente, equilátero.

Segue desse fato que $\overline{P A}+\overline{P B}+\overline{P C}=$ $\overline{P A}+\overline{P P^{\prime}}+\overline{P^{\prime} B^{\prime}}$. Mas, observe que a soma $\overline{P A}+\overline{P P^{\prime}}+\overline{P^{\prime} B^{\prime}}$ é minimizada quando os pontos $A, P, P^{\prime}$ e $B^{\prime}$ estão todos contidos numa mesma reta. Supondo que os pontos $A, P$ e $P^{\prime}$ estejam contidos numa mesma reta, e utilizando o fato de que $\operatorname{med}\left(C \hat{P} P^{\prime}\right)=60^{\circ}$, concluímos que med $(A \hat{P} C)=120^{\circ}$. De modo análogo, supondo que os pontos $P, P^{\prime}$ e $B^{\prime}$ estejam contidos numa mesma reta, e utilizando o resultado de que med $\left(C \widehat{P}^{\prime} P\right)=60^{\circ}, \quad$ concluímos que med $\left(B^{\prime} \widehat{P}^{\prime} C\right)=120^{\circ}$. Portanto, o ponto $P$ que minimiza a soma $\overline{P A}+\overline{P B}+\overline{P C}$ é tal que os ângulos formados entre $P A, P B$ e $P C$, tomados dois a dois, medem cada um $120^{\circ}$.

Um modo prático, para obter o ponto mínimo $P$ é devido ao matemático inglês Thomas Simpson (1710-1761). Simpson mostrou que o ponto mínimo $P$ é a intersecção das três circunferências circunscritas respectivamente aos triângulos equiláteros construídos sobre cada lado do triângulo $A B C$, como mostra a figura 5 .

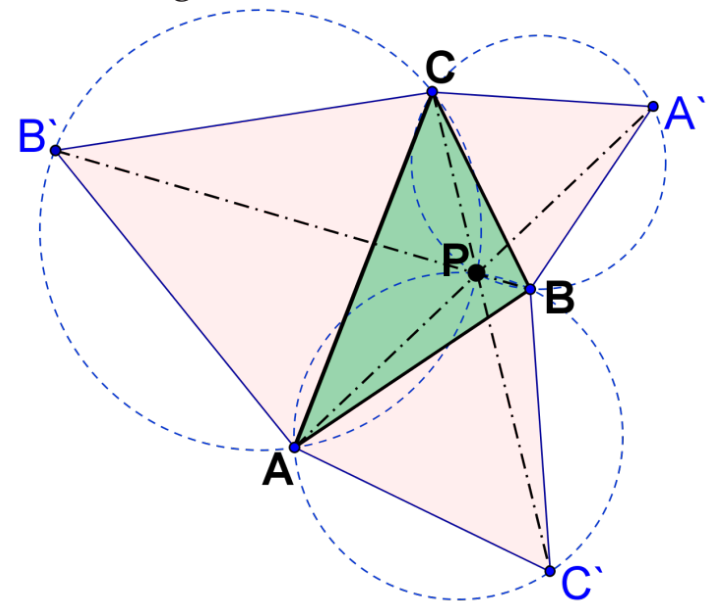

Figura 5 - Construção de Simpson para obtenção de $\boldsymbol{P}$
Além disso, Simpson mostrou que o ponto $P$ pode ser obtido, ligando-se, respectivamente, os vértices $A, B$ e $C$ aos vértices externos $A^{\prime}, B^{\prime} e C^{\prime}$ dos triângulos equiláteros $B C A^{\prime}, A C B^{\prime}$ e $A B C^{\prime}$.

Não apresentaremos aqui a demonstração desse resultado, mas remetemos os leitores interessados à referência bibliográfica (COURANT, 2000, p. 436).

O matemático Jacob Steiner (1796-1863) trabalhou na generalização do problema de Fermat. A generalização desse problema tornou-se interessante porque Steiner abandonou a busca por um único ponto P. Em vez disso, Steiner passou a procurar "redes mínimas" de comprimento total mais curto. Segundo Courant e Robbins (2000, p. 436),

"Dados $n$ pontos $A_{1}, A_{2}, \ldots, A_{n}$, encontre um sistema conectado de segmentos de retas de comprimento total mais curto tal que quaisquer dois pontos dados possam ser unidos por uma poligonal formada por segmentos do sistema."

O aspecto da solução desse problema dependerá da disposição dos $n$ pontos dados. Steiner demonstrou que, no caso de $n$ pontos, haverá no máximo $n-2$ intersecções múltiplas, em cada uma das quais três segmentos se encontram em ângulos de $120^{\circ}$. A figura 6 exibe alguns exemplos de redes mínimas de Steiner. 


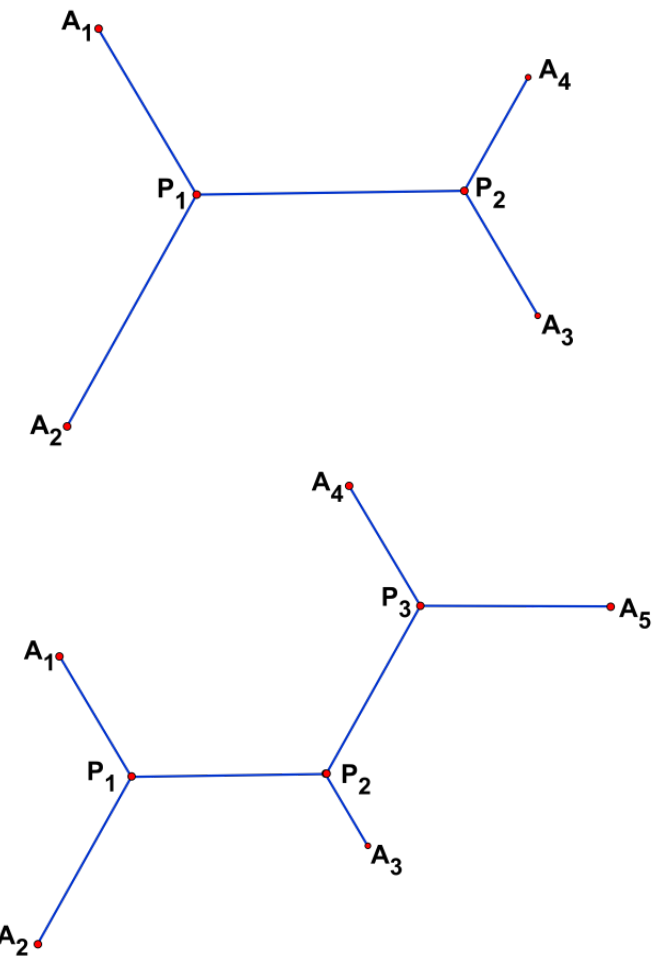

Figura 6 - Redes de Steiner com várias conexões

Vamos analisar o caso da rede mínima que une os vértices de um retângulo. Nesse caso, facilmente se verifica que a solução consiste em cinco segmentos com duas intersecções múltiplas onde três segmentos se encontram em ângulos de $120^{\circ}$.

Mostraremos que essa rede mínima é tal que as duas interconexões múltiplas, $P_{1}$ e $P_{2}$ são simétricas em relação aos eixos de simetria, vertical e horizontal, do retângulo, como mostra a figura 7 .

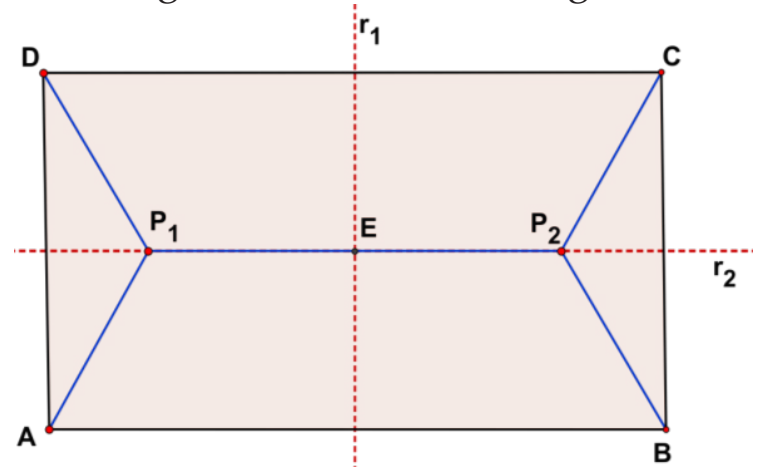

Figura 7 - Solução do problema de Steiner para os vértices do retângulo $\mathrm{ABCD}$
De fato, seja o retângulo $A B C D$ com eixos de simetria vertical e horizontal $r_{1}$ e $r_{2}$, respectivamente, que se intersectam no ponto $E$. Admitamos que $P_{1}$ e $P_{2}$ sejam vértices das duas intersecções múltiplas da rede mínima que une $A, B, C$ e $D$.

Supondo, sem perda de generalidade, que $P_{1}$ e $P_{2}$ estão localizados em lados diferentes de $r_{1}$. Afirmamos que, nesse caso, $P_{1}$ e $P_{2}$ devem ser simétricos em relação à $r_{1}$. De fato, se assim não ocorresse, a rede que une $A D E$ teria comprimento diferente da rede que une $C B E$, mas isso é impossível, pois $A D E$ e $C B E$ são simétricos em relação à $r_{1}$.

Utilizando o mesmo raciocínio demonstra-se que, se $P_{1} e P_{2}$ estão em semiplanos diferentes em relação à $r_{2}$, então $P_{1}$ e $P_{2}$ devem também ser simétricos em relação à $r_{2}$.

Esse resultado mostra que, dada uma malha ligando os quatro vértices de um retângulo, essa malha terá como eixos de simetria os mesmos eixos horizontal e vertical do retângulo $A B C D$.

Logo, para obter a rede mínima que une os vértices de $A B C D$ basta tomar a intersecção $E$ dos eixos de simetria $r_{1} e r_{2}$ de $A B C D$ e determinar os pontos de Fermat $P_{1}$ e $P_{2}$ dos triângulos $A D E$ e $C B E$ ou dos triângulos $A B E$ e $C D E$.

\section{Aspectos metodológicos}

Verificar o desenvolvimento dos alunos em geometria, num projeto de modelagem, exige a construção de um encaminhamento metodológico adequado para organizar o experimento, selecionar os instrumentos de coleta de dados e analisar os resultados obtidos. 
Nesse caso, os resultados obtidos estão presentes nos dados coletados nas produções dos alunos que incluem diálogos, registros escritos, esboços, construções geométricas feitas no caderno, os painéis e a maquete confeccionada para a apresentação final do projeto.

Além disso, entendemos que o desenvolvimento em geometria se evidencia nas produções dos alunos, quando demonstram as capacidades de identificar o problema, procurar, selecionar e interpretar informações relativas ao problema, formular hipóteses e prever resultados, selecionar estratégias de resolução, interpretar e criticar resultados em face da realidade, distinguir e utilizar raciocínios dedutivos e indutivos, fazer e validar conjecturas, experimentar e recorrer a modelos, esboços, fatos conhecidos, relações e propriedades, discutir ideias e produzir argumentos convincentes.

Para identificar essas competências optamos pela abordagem qualitativa, que segundo Bogdan e Biken (1994), citados em Ludke e André (1986, p.11),

“tem o ambiente natural como sua fonte direta de dados e o pesquisador como seu principal instrumento" e, "envolve a obtenção de dados descritivos, obtidos no contato direto do pesquisador com a situação estudada, enfatiza mais o processo do que o produto e se preocupa em retratar a perspectiva dos participantes".

Considerando que as normas da instituição proíbem filmagens ou gravações de entrevistas, optamos pela análise dos registros escritos e artefatos confeccionados pelos alunos, complementados pelas nossas anotações em diário de campo de conversas com os alunos.

A parte experimental desse projeto de modelagem matemática foi realizada ao longo de quatro semanas com 13 adolescentes, faixa etária de 14 a 16 anos, internados num Centro de Socioeducação do sul do país. A internação desses adolescentes decorre da aplicação de medidas socioeducativas em função da prática de atos infracionais.

A internação desses adolescentes é relevante nesse estudo por três razões: Primeiro, o fato dos adolescentes estarem internados implica em mais tempo dedicado a atividades de natureza educativa (aulas de matemática, por exemplo, são 8 por semana). Segundo, essas atividades devem obrigatoriamente promover o fortalecimento dos princípios éticos da vida social, deve trabalhar os valores humanos e novos e apropriados conceitos de vida. Terceiro, por causa da segurança, o número de alunos por turma é muito reduzido, girando em torno de cinco alunos por turma.

Os 13 adolescentes que participaram desse projeto pertenciam a duas turmas de Ensino Fundamental, modalidade Educação de Jovens e Adultos - EJA. Essas turmas são multisseriadas, ou seja, cada aluno matricula-se na disciplina de matemática num módulo correspondente à série em que se encontra no ensino regular. $\mathrm{Na}$ realização das atividades desse projeto de modelagem matemática, porém, os 
alunos trabalharam coletivamente e com os mesmos conteúdos de geometria.

A escolha do tema foi realizada com os alunos a partir de uma sugestão do professor (primeiro autor desse artigo) de trabalhar conteúdos de matemática utilizando imagens aéreas extraídas do Google Earth. Argumentamos com os alunos que o software Google Earth possui algumas ferramentas, tais como régua, legenda de escala, gráfico de elevação de terreno e inserção de polígonos que conduzem a muitos problemas, envolvendo a otimização de grandezas geométricas.

Dentre as sugestões feitas pelos alunos, apareceu a proposta de elaborar um projeto de revitalização e reforma de uma praça pública de Londrina - praça Rocha Pombo. A ideia inicial, apresentada pelos alunos, era "tirar" as medidas dessa praça no Google Earth (figura 8), confeccionar duas maquetes, uma da praça atual e outra da praça reformada e revitalizada, e apresentar esse projeto num evento de confraternização.

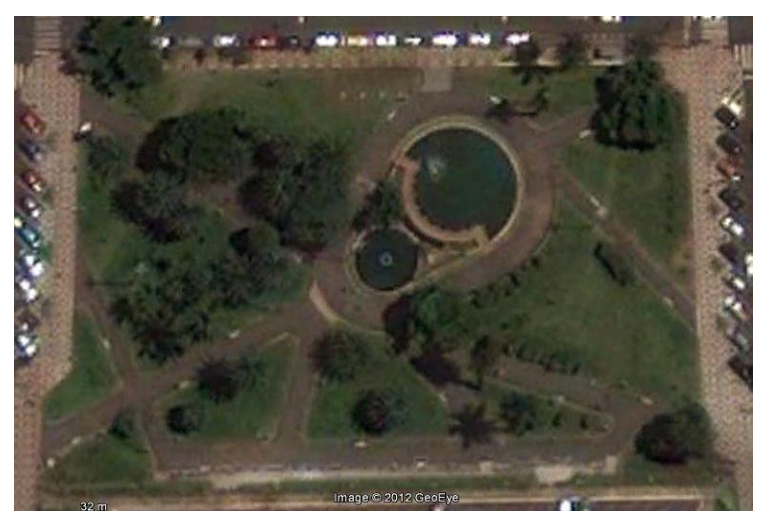

Figura 8 - Imagem aérea da Praça Rocha Pombo

A figura 9 mostra a maquete construída com as modificações sugeridas pelos alunos para a praça.

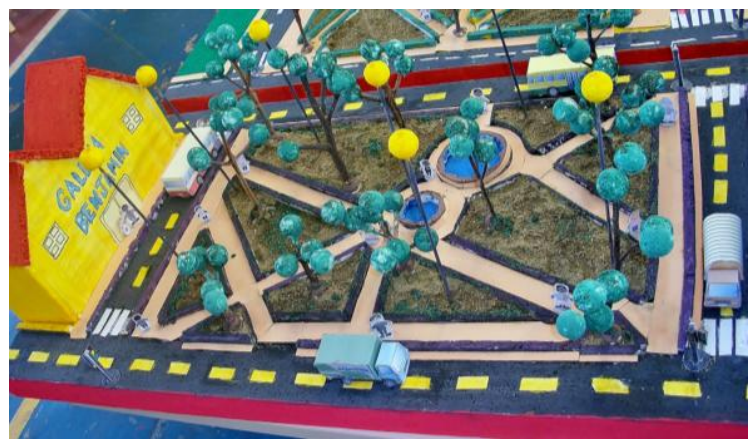

Figura 9 - Maquete da Praça Rocha Pombo

Na elaboração de um projeto de praça pública, diversos problemas de otimização podem ser abordados, conforme (ROBBA, 2002). Minimizar os custos com material de construção ou o comprimento dos caminhos que interligam os diversos pontos da praça. Maximizar as áreas dos canteiros ou os espaços de lazer são exemplos de problemas que envolvem otimização geométrica.

Discutimos com os alunos esses problemas e escolhemos estudar com eles o problema de obter soluções para minimizar a rede de caminhos que interligam os diversos pontos da praça Rocha Pombo. E, desse modo, o estudo do problema escolhido com os alunos, se desdobrou em três atividades, cada uma envolvendo objetivos específicos, como detalha o Quadro 1. 
Quadro 1 - Atividades de modelagem matemática e seus respectivos objetivos de aprendizagem

\begin{tabular}{ll}
\hline ATIVIDADE & OBJETIVOS DE APRENDIZAGEM \\
\hline 1)Caminhos mínimos & - Realizar medidas de distâncias e ângulos; \\
numa praça com & - Utilizar rotações na resolução de problemas; \\
três pontos de & - Reconhecer condições do ponto de mínimo; \\
acesso & - Resolver e aplicar o problema de Fermat- \\
& Steiner. \\
\hline 2)Caminhos mínimos & - Realizar medidas de distâncias e ângulos; \\
numa praça com & - Obter o ponto de Fermat utilizando simetria; \\
mais de três pontos & - Reconhecer redes de Fermat; \\
de acesso & - Utilizar o problema de Fermat-Steiner para \\
& obter experimentalmente pontos de mínimo \\
\hline & - Elaborar um projeto de praça aplicando os \\
3)Projeto e confecção & conhecimentos adquiridos; \\
da maquete da & - Avaliar projetos de praças; \\
praça & - Apresentar o trabalho realizado, justificando as \\
& escolhas. \\
\hline
\end{tabular}

\section{Resultados: as produções dos alunos}

O desenvolvimento das competências de investigação e compreensão dos alunos em geometria foi observado ao longo das três atividades realizadas. Procuramos focalizar ao longo dessas atividades o desenvolvimento da capacidade de investigação, argumentação, o raciocínio indutivo e dedutivo em geometria, mediante a experimentação, análise e comunicação de problemas de otimização.

\section{Atividade 1: Caminhos mínimos numa praça com três pontos de acesso}

Investigando imagens aéreas obtidas no Google Earth, verificamos com os alunos que um dos problemas da Praça Rocha Pombo é a conservação do espelho d'água e do chafariz. Assim, no projeto de reforma dessa praça os alunos deveriam apresentar soluções para esse problema. Dessa discussão, obtivemos algumas sugestões dos alunos no sentido de melhorar a localização desses elementos centrais da praça.

De fato, tanto o chafariz quanto o espelho d'água estão localizados de forma assimétrica em relação à área total da praça. Já havíamos debatido com os alunos, que um dos problemas no projeto de uma praça pública é saber onde construir o chafariz, ou espelho d'água ou onde colocar a estátua que é o elemento central de uma praça. A elaboração do novo projeto de praça deveria levar em conta que as distâncias entre os pontos de acesso da praça até seus elementos centrais deveriam ser melhoradas. 
Para familiarizar os alunos com esse problema, propomos que tentassem encontrar um ponto que minimizasse a soma das distâncias aos vértices na imagem área da Praça do Triângulo, localizada em Goiânia (figura 10). Mais precisamente, desafiamos os alunos a encontrar um ponto um ponto $\mathrm{P}$ da Praça do Triângulo de modo que a soma das distâncias desse ponto até os cantos A, B e C da praça seja a menor possível.

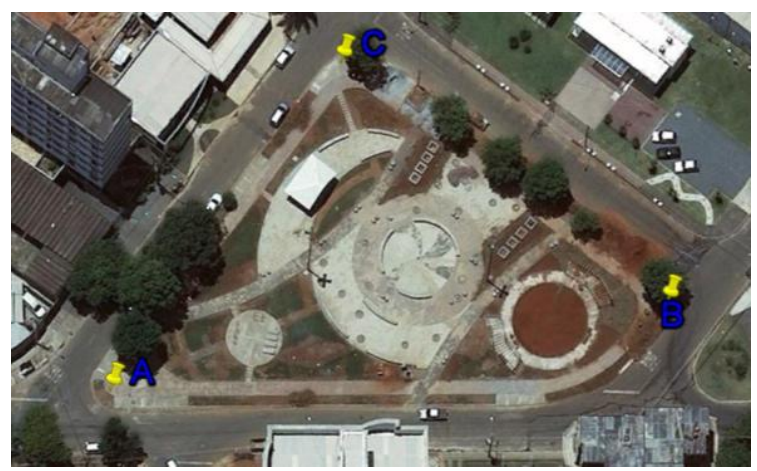

Figura 10 - Imagem aérea da praça do

Triângulo em Goiânia

O objetivo desse problema é levar os alunos a perceber que a soma das distâncias aos vértices é minimizada quando cada ângulo formado entre os segmentos que ligam os vértices ao ponto $P$ mede $120^{\circ}$.

As ações dos alunos nesse caso foram: marcaram sobre a imagem da praça cinco pontos diferentes; utilizando régua e transferidor mediram as distâncias desses pontos até os três vértices da praça; mediram também os ângulos entre os segmentos que unem esses pontos aos vértices e organizaram os dados numa tabela, a fim de comparar a relação entre os ângulos e soma das medidas dos lados.

Essa experiência e a discussão em torno dos dados da tabela levaram os alunos a apresentar a hipótese de que a soma era sempre menor quanto mais próximo os três ângulos estavam de $120^{\circ}$ (figura 11).

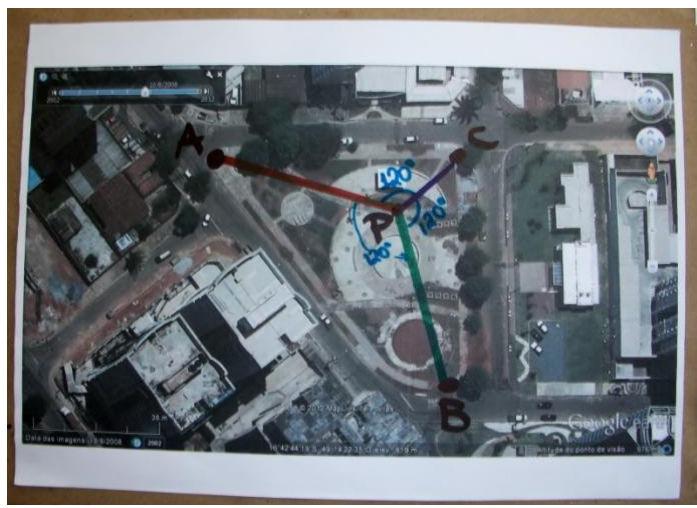

Figura 11 - Solução do problema de Fermat-Steiner

Estimulamos os alunos a tentarem obter uma explicação para esse resultado. Para auxiliá-los, discutimos com eles a solução dada ao problema de Heron.

Solicitamos que recortassem em cartolina três formas triangulares iguais e tentassem, com esses triângulos, obter uma configuração na qual os segmentos ligando os vértices do triângulo ao ponto $\mathrm{P}$ marcado em seu interior ficariam realmente alinhados numa reta.

A solução obtida com o auxílio do professor foi baseada no "método de rotação". Primeiro, os alunos marcaram num triângulo $A B C$, recortado em cartolina, um ponto $P$ qualquer. Em seguida, traçaram os segmentos $A P, B P$ e $C P$ e reproduziram essa construção nos dois triângulos.

Ilustraremos as ações dos alunos com a figura 12 . 


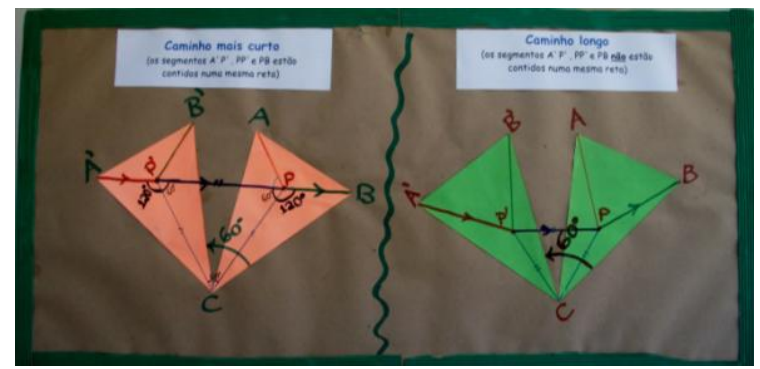

Figura 12 - $\mathrm{O}$ triângulo $A B C$ é girado em $60^{\circ}$, obtendo-se $A^{\prime} B^{\prime} C$

Ao fazer uma rotação em torno do vértice $C$ com um ângulo $60^{\circ} \mathrm{em}$ sentido horário, os alunos perceberam que o triângulo $C P P^{\prime}$, obtido pela rotação, era equilátero. De fato, os alunos notaram que $C P=C P^{\prime} \mathrm{e}$, com isso, concluíram que $C P P^{\prime}$ é isósceles. E, como o ângulo $P \hat{C} P^{\prime}$ mede $60^{\circ}$ os outros dois ângulos também medem $60^{\circ}$, e, com isso, os alunos justificaram que $C P P^{\prime}$ é equilátero.

Os alunos concluíram também que a $\overline{A P}+\overline{B P}+\overline{C P}=\overline{A^{\prime} P^{\prime}}+\overline{P^{\prime} P}+\overline{P B}$. Mas essa soma é minimizada quando os pontos $A^{\prime}, P^{\prime}, P$ e $B$ estão contidos numa mesma reta. Com essa observação, os alunos chegaram à conclusão de que se $A^{\prime}, P^{\prime}$ e $P$ estão contidos numa mesma reta e, como o ângulo $C \widehat{P}^{\prime} P$ mede $60^{\circ}$, então o ângulo $A^{\prime} \widehat{P}^{\prime} C$ deve medir $120^{\circ}$. Do mesmo modo, se os pontos $P^{\prime}, P$ e $B$ estão contidos numa mesma reta e o ângulo $P^{\prime} \hat{P} C$ mede $60^{\circ}$ então o ângulo $C \widehat{P}^{\prime} B$ também mede $120^{\circ}$.

Seguindo esse raciocínio, os alunos perceberam que o ponto $P$ que minimiza a soma $\overline{A P}+\overline{B P}+\overline{C P}$ é onde as retas $A P, B P$ e $C P$ formam três ângulos iguais de $120^{\circ}$.

A partir dessas construções formalizamos que encontrar um ponto $P$ no triângulo $A B C$ de modo que a soma $\overline{A P}+\overline{B P}+\overline{C P}$ seja mínima, equivale a encontrar um ponto de $A B C$ em que os ângulos entre $A P, B P$ e $C P$ tenham a mesma medida.

Para sistematizar esses resultados, explicamos aos alunos método de Simpson, conforme citado anteriormente para determinar o ponto $P$ para o caso do triângulo em que nenhum ângulo é maior que $120^{\circ}$.

Finalizamos essa atividade, sistematizando os seguintes conteúdos abordados: propriedades de triângulos isósceles (os dois lados iguais formam ângulos iguais com o lado diferente e, nos triângulos isósceles em que os ângulos são todos iguais, é o equilátero).

\section{Atividade 2: Caminhos mínimos em praças com quatro ou mais pontos de acesso}

Esta atividade requer o uso de algumas ideias principais abordadas no problema da atividade anterior. A finalidade é oportunizar aos alunos uma noção mais geral do que são redes de caminhos de comprimento mínimo. A conjectura inicial era que, numa praça com vários acessos, para interligar esses acessos com uma rede de caminhos que tenha o menor comprimento possível, os pontos de interconexões desses caminhos devem ter ângulos com $120^{\circ}$. Esse resultado é uma generalização do problema estudado no encontro anterior.

Utilizando esse argumento, explicamos que redes de caminhos com interconexões determinando ângulos iguais a $120^{\circ}$, possuem comprimento mais curtos. Explicamos que os pontos de interconexão nesses caminhos, os chamados pontos de Fermat, podem ser obtidos experimentalmente, utilizando 
folhas transparentes, tipo slides, com três retas conectadas formando ângulos iguais a $120^{\circ}$.

Com essa explicação e com o objetivo de retomar os objetivos do projeto de Modelagem, propusemos aos alunos o problema de localizar dois pontos $P_{1} e P_{2}$, onde poderiam ser construídos dois chafarizes na Praça Rocha Pombo, de modo que esses pontos fossem as conexões de uma rede de caminhos ligando os cantos da praça. Como essa rede deve ter comprimento mínimo, esses pontos $P_{1}$ e $P_{2}$, devem determinar ângulos que medem $120^{\circ}$.

Os alunos procuraram então descobrir os pontos $P_{1}$ e $P_{2}$ numa imagem impressa da Praça Rocha Pombo. Para isso desenharam três retas com ângulos de $120^{\circ}$ entre si em duas folhas de plásticos transparentes e deslizando-as sobre a imagem impressa da Praça Rocha Pombo, descobriram dois possíveis caminhos mínimos para essa praça com dois pontos de Fermat, onde deveria ser construído um chafariz. Assim obtiveram as soluções apresentadas na figura 13.

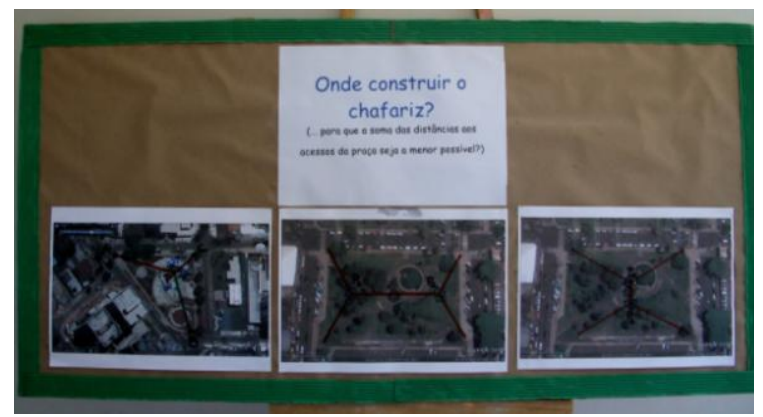

Figura 13 - Caminhos mínimos na praça Rocha Pombo

Para testarem se essa rede de caminhos realmente tinha comprimento mínimo, os alunos compararam com outros caminhos possíveis. O primeiro deles é construir as duas diagonais $A C$ e $B D$ da praça. Outro caminho testado foi construir a diagonal $A C$ e determinar os pontos $P_{1}$ e $P_{2}$ como sendo os pés das alturas dos triângulos $A C B$ e $A B D$, como mostram a figura 13. Assim os alunos perceberam, experimentalmente, que o caminho em que $P_{1}$ e $P_{2}$ determinam ângulos de $120^{\circ}$ era ainda o mais curto.

$\mathrm{O}$ avanço na atividade foi considerar mais pontos de acesso na construção da rede de caminhos. O primeiro problema era obter uma rede de caminhos sobre uma praça retangular com 6 pontos de acessos e três pontos de conexões (três chafarizes). $\mathrm{O}$ segundo problema era obter, numa praça também retangular com 6 pontos de acesso, uma rede de caminhos mínimos com 4 conexões. Novamente as soluções apresentadas pelos alunos foram obtidas construindo experimentalmente os pontos de mínimo, utilizando as folhas plásticas com os desenhos de retas formando $120^{\circ}$.

No primeiro problema foram utilizadas 3 folhas plásticas, pois os alunos precisam encontram a rede de caminhos com três conexões. No segundo problema em que eram necessárias 4 conexões foram utilizadas 4 folhas plásticas. As soluções apresentadas pelos alunos encontram-se ilustradas na figura 14.

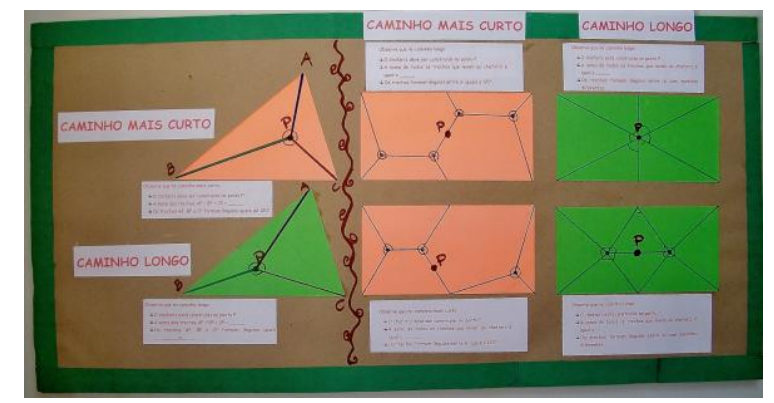

Figura 14- Comparação entre soluções do problema de Fermat-Steiner 
No painel, estão expostas as soluções dos alunos para os problemas de encontrar redes de caminhos mínimos. Solicitamos também aos alunos na resolução desses problemas que comparassem as redes de caminhos em que os ângulos de interconexões formassem $120^{\circ}$ com outras em isso não ocorria. Comparando os comprimentos totais dessas redes de caminhos os alunos puderam verificar experimentalmente a propriedade de mínimo das redes de Steiner.

\section{Atividade 3: A confecção da maquete e a apresentação do trabalho}

Com esta atividade os alunos tiveram oportunidade de retomar os problemas de otimização estudados. Inicialmente os alunos elaboraram um desenho, com a finalidade de usá-lo como projeto para a construção da maquete da praça Rocha Pombo. Combinamos que cada aluno faria seu desenho, mas apenas um seria escolhido. $\mathrm{O}$ desenho escolhido seria aquele que contemplasse os resultados aprendidos ao longo do estudo dos problemas de otimização, ou seja, no projeto deveria aparecer uma rede de caminhos de comprimento mínimo (rede de Steiner) interligando os pontos de acesso da praça aos pontos centrais.

Os alunos passaram a trabalhar ativamente na elaboração dos desenhos. Várias ideias foram apresentadas pelos alunos. Depois que todos os alunos entregaram seus projetos, passamos a discutir com eles as ideias sugeridas para a reforma da praça. Assim, cada aluno podia defender seu projeto e todos poderiam apontar os problemas e vantagens no projeto apresentado. Ao final da avaliação do projeto obtivemos um que foi do consenso de todos.

A fotografia apresentada na figura 15 mostra a maquete da praça feita a partir do projeto elaborado pelos alunos.

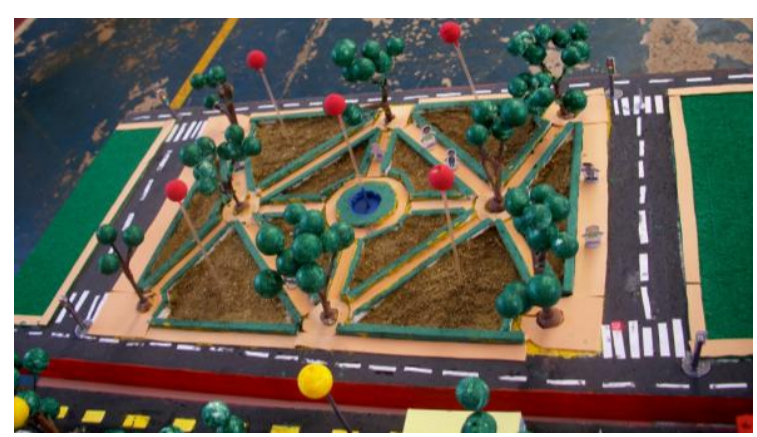

Figura15 - Maquete da praça construída pelos alunos

Observe que os lados maiores da praça, (cima e embaixo na foto) possui caminhos formando ângulos iguais com esses lados. Esse detalhe atende o primeiro critério. Além disso, observe que existem dois pontos de conexão de uma rede de caminhos que formam ângulos de $120^{\circ}$. Portanto, este projeto apresenta uma rede de Steiner com dois pontos de conexão e, assim, atende ao segundo critério.

Para desenvolver a atividade, foi utilizada uma semana de aula. Onde foram confeccionadas as maquetes e preparada a apresentação dos trabalhos. Como essa apresentação ocorreria em um evento de confraternização dos alunos suas famílias, professores e funcionários do Centro, houve particular motivação dos alunos em confeccionar as maquetes e os painéis que exibiriam sua compreensão dos problemas de otimização.

Assim, além das maquetes, foram organizados nove painéis que serviram para que os alunos apresentassem as atividades de Modelagem desenvolvidas 
ao longo dos oito encontros a toda comunidade presente.

As figuras 16(a) e 16(b) mostram como foram dispostos os painéis para a apresentação dos trabalhos.

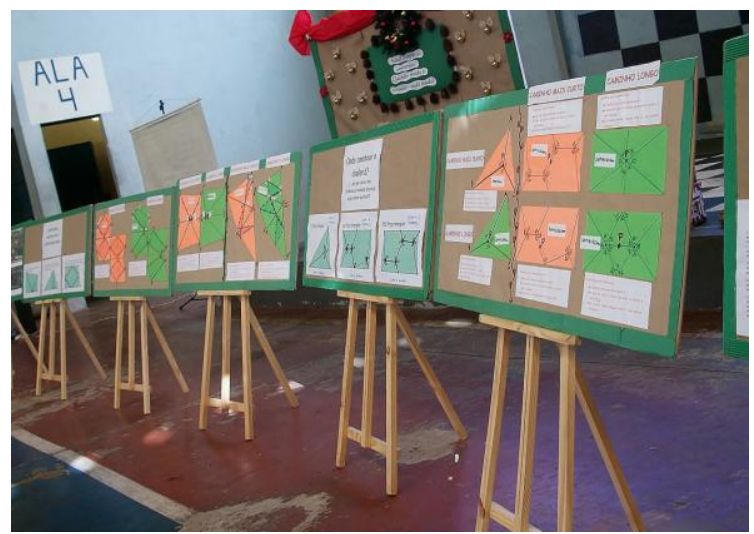

Figura 16(a) - Apresentação do trabalho final dos alunos

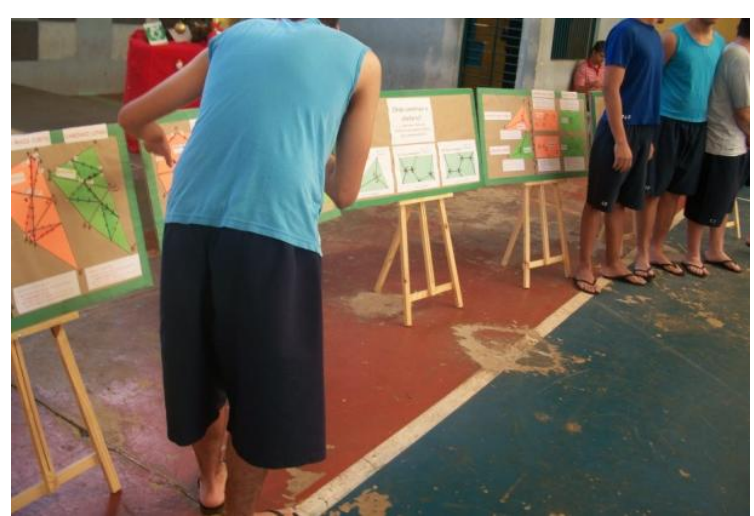

Figura 16(b) - Apresentação do trabalho final dos alunos

Um aspecto importante desses painéis é apresentar as argumentações dos alunos com relação as suas construções utilizando demonstrações visuais. Roger (2000) caracteriza como demonstrações visuais às construções geométricas que auxiliam na percepção das propriedades geométricas empregadas na resolução de um problema. Neste trabalho, as demonstrações visuais foram feitas pelo método de reflexão, no caso do problema de Heron, e rotação no caso do problema de Fermat-Steiner. Outro aspecto importante é a comparação entre caminho mínimo obtido resolvendo o problema de otimização geométrica e o chamado caminho longo. Assim, em cada painel pode-se visualizar as propriedades ou condições geométricas da solução do problema, assim como também se pode observar quando essas propriedades não são atendidas.

\section{Discussão dos resultados}

Apontamos, na introdução deste artigo, que o objetivo desse estudo é verificar o desenvolvimento das competências de investigação e compreensão dos alunos em geometria a partir da exploração de um problema de otimização geométrica numa atividade de modelagem matemática.

As evidências desse desenvolvimento foram procuradas nas produções dos alunos e, neste trabalho, apontamos e discutimos três dessas evidências: (1) compreensão do significado de investigar um problema real, mobilização de conhecimentos prévios na resolução do problema e (3) comunicação e argumentação em geometria empregando imagens visuais.

\section{Compreensão do significado de investigar um problema real}

Quando discutimos o tema com os alunos e apresentamos a eles as imagens áreas de praças, pensaram que 0 trabalho seria um tipo trabalho de pesquisa, no qual procurariam na internet textos sobre $\mathrm{o}$ assunto, selecionariam aspectos mais importantes do tema, montariam um texto dentro das normas (capa, introdução, referências, 
etc.) e entregariam ao professor para ser avaliado. Achavam também que iríamos inventar problemas sobre tema "praças" envolvendo cálculos, problemas com "continhas" para praticar exercícios.

Entretanto, ao longo das atividades e, principalmente, quando tiveram seus projetos de praça avaliados, levando-se em conta critérios matemáticos, perceberam a relevância dos conteúdos de geometria estudados naquele período.

Nesse sentido essa experiência de ensino representou para os alunos uma investigação autêntica em matemática, pois os alunos compreenderam que conceitos e resultados da geometria podem, de fato, melhorar (otimizar) vários aspectos de uma praça pública.

Além disso, outro aspecto observado que torna esse trabalho de modelagem uma autêntica investigação em matemática é que, em todas as aulas, os alunos utilizavam sua própria experiência de vida para discutir aspectos dos problemas abordados.

\section{Mobilização de conhecimentos prévios na resolução do problema}

A experiência dos alunos foi fundamental para que compreendessem a natureza dos problemas abordados e as estratégias para sua resolução. Problemas de otimização geométrica em que se minimizam comprimentos ou maximiza áreas de figuras podem ser perfeitamente compreensíveis quando falamos em obter caminhos mais curtos ou canteiros que cabem mais plantas numa praça. Além disso, os alunos perceberam que o abordado não era trivial, ou seja, não era um problema do tipo apresentado nos livros didáticos que mostra a pergunta logo depois fórmula que dá a resposta. Para obter e compreender a solução desses problemas, os alunos levantaram conjecturas, testaram hipóteses, realizaram experimentos, enfim, empregaram seus próprios saberes para chegar ao saber sistematizado da geometria.

De fato, os alunos também mobilizaram conhecimentos prévios para analisar as imagens aéreas do Google Earth. Desde o início, quando vinculamos a escolha do tema ao uso de imagens do Google Earth para coletar dados percebemos que esse fato teria grande efeito motivador. Além da motivação, as imagens do aplicativo também tornaram mais plausíveis os problemas estudados, uma vez que as imagens obtidas eram representações de objetos reais que podiam ser explorados e nos quais se podiam reconhecer conhecimentos geométricos.

\section{Comunicação e argumentação em geometria empregando imagens visuais}

Os alunos que participaram do desenvolvimento dessas atividades tinham pouco conhecimento de geometria. Eles sabiam reconhecer figuras simples como triângulos, retângulos, quadrados. Tinham uma noção vaga de ângulo, conheciam algumas fórmulas para o cálculo de áreas, mas em geral não compreendiam o significado do conceito de área. Assim, procuramos, desde o início, ampliar o uso de noções de geometria nas atividades de modelagem e criar nos 
alunos o hábito de explicar e justificar por que as soluções dos problemas eram válidas. Em cada problema solucionado, uma grande parte do tempo dos encontros era destinada a elaborar uma justificava plausível para essas soluções.

$\mathrm{O}$ fato dos alunos terem que apresentar e justificar as soluções obtidas na apresentação final do projeto tornou o trabalho com argumentação e raciocínio indutivo e dedutivo possível ao longo do desenvolvimento das atividades.

De fato, a compreensão da resolução dos problemas se apoia, nesse trabalho, em aspectos visuais, ou seja, as soluções dos problemas poderiam perfeitamente se encaixar no caso das demonstrações sem palavras. Segundo Roger (2000, p. 56), para compreender essas demonstrações, necessita-se de um instante de abstração olhando para a figura e/ou a fórmula, relacionando ambas e fazendo a leitura correta. Das observações que fizemos dos alunos, notamos que eles rapidamente assimilam essas demonstrações visuais baseadas no método de reflexão e incorporam suas ideias nas suas justificativas $\mathrm{e}$ argumentações.

Observamos que nas demonstrações visuais utilizaram termos como deslizar, refletir, girar, recortar, mover, colar, recolocar, alinhar, sobrepor, reagrupar, decompor, etc. Quando os alunos explicaram a solução dos problemas de Heron e de Fermat-Steiner, utilizando alguns desses termos, evidenciaram a compreensão da ideia de reflexão, de rotação, a propriedade dos triângulos isósceles serem equilátero no caso de serem equiângulos, o conceito de ângulo como rotação, a noção de triângulos congruentes e a noção de colinearidade.

\section{Referências}

ALMEIDA, L. M. W., \& BRITO, D. S. (2005).Atividades de Modelagem Matemática: que sentido os alunos podem lhe atribuir?. Ciência e Educação (UNESP), v. 11, p. 1-16.

BARBOSA, Jonei Cerqueira. Modelagem Matemática e os Professores: a Questão da Formação. Bolema, 15, p. 5-23. Rio Claro: 2001.

BASSANEZI, Rodney C. Ensinoaprendizagem com modelagem matemática. São Paulo: Contexto, 2002.

BOGDAN, R.; BIKLEN, S. Características da investigação qualitativa. In: Investigação qualitativa em educação: uma introdução à teoria e aos métodos. Porto, Porto Editora, 1994. p.47-51

BRASIL. Orientações Curriculares para o Ensino Médio. Ciências da Natureza, Matemática e suas Tecnologias. Brasília: MEC, SEB, 2006.

BRASIL. Ministério da Educação, Secretaria da Educação Média e Tecnológica. Parâmetros Curriculares Nacionais: ensino médio. Brasília: Ministério da Educação, 1999.

BRASIL. Secretaria de Educação Média e Tecnológica. PCN+ Ensino Médio: orientações educacionais complementares aos Parâmetros Curriculares Nacionais. Ciências da Natureza, Matemática e suas Tecnologias. Brasília: MEC, SEMTEC, 2002. 
BRASIL. Ministério da Educação. Secretaria de Educação Fundamental. Parâmetros Curriculares Nacionais: Matemática. ( $3^{\circ}$ e $4^{\mathrm{o}}$ ciclos do ensino fundamental). Brasília: MEC, 1998.

BRITO, D; ALMEIDA, L. M. W. O conceito de função em situações de Modelagem Matemática. Revista: Zetetikê ,v.12, n.23 jan/jun . p. 42-61, 2005.

BRITO, D. S. Problemas de otimização geométrica aplicados ao estudo de praças: Uma experiência de ensino com atividades de modelagem matemática. Londrina, 2013. Dissertação de Mestrado - Mestrado Profissional em Matemática em Rede Nacional- Universidade Estadual de Londrina.

COURANT, Richard; ROBBINS, Herbert. O que é matemática? Uma abordagem elementar de métodos e conceitos. Rio de Janeiro: Ciência Moderna, 2000.

FIGUEIREDO, D.G. Problemas de Máximo e Mínimo na Geometria Euclidiana em Matemática Universitária, n 9/10, 1989.

LÜDKE, Menga e ANDRÉ, Marli E. De. Pesquisa em Educação: Abordagens qualitativas. São Paulo: EPU, 1986.

MARTIN C. Roberge and Linda C. Cooper, Map Scale, Proportion, and Google Earth in Mathematics Teaching in Middle School Vol 15, No.8, April 2010

NIVEN, I. (1981). Maxima and minima without calculus. USA: Mathematical Association of America.
ROBBA, F; MACEDO, S. S. Praças Brasileiras. (Public Squares in Brazil). São Paulo: Edusp: Imprensa oficial do Estado. 2002, 312p.

ROGER B. N. Proofs Without Words II Exercises in Visual Thinking, The Mathematical Association of America, 2000 